\title{
Nonvitamin K Antagonist Oral Anticoagulants in Patients with Extreme Body Weights: One Size Fits All?
}

\author{
So-Ryoung Lee ${ }^{1}$ Eue-Keun Choi ${ }^{1}$ \\ ${ }^{1}$ Department of Internal Medicine, Seoul National University \\ Hospital, Seoul, Korea \\ Thromb Haemost 2021;121:115-117.
}

Although nonvitamin $\mathrm{K}$ antagonist oral anticoagulants (NOACs) have generally shown comparable efficacy and better safety compared with warfarin, atrial fibrillation (AF) patients with extreme body weights have been underrepresented in pivotal clinical trials. Low-body-weight (LBW) patients with $\mathrm{AF}$ usually have other comorbidities, resulting in higher risks of major bleeding and mortality. A consensus statement from the European Society of Cardiology Working Group on Thrombosis recommended that edoxaban dose be halved ( $30 \mathrm{mg}$ once daily) in patients with $\mathrm{LBW}(\leq 60 \mathrm{~kg})$ and apixaban dose be halved ( $2.5 \mathrm{mg}$ twice daily) if LBW is combined with renal impairment or old age. ${ }^{1}$ Rivaroxaban did not show clinically relevant changes in plasma concentration in patients weighing $<50 \mathrm{~kg}$ and does not require dose reduction according to body weight. Of note, dabigatran data in patients with extreme LBW (below $50 \mathrm{~kg}$ ) are limited. In general, however, there are still limited data on whether fixed-dose NOACs could be safely and effectively prescribed in patients with extreme body weights.

Asian patients with AF have generally shown poor quality of warfarin control and a higher risk of intracranial hemorrhage (ICH) with warfarin use. Subsequently, NOACs were introduced, and these patients showed similar or better results with NOACs compared with warfarin in a metaanalysis of major pivotal trials. ${ }^{2}$ However, LBW poses another challenge for stroke prevention in Asian patients with AF.

AF patients with LBW are more prevalent in the Asian population. In the pivotal trials, the mean body weight of Asian patients with AF was lower than that of non-Asian patients ( - Table 1 ). Recently, we reported the effectiveness and safety of NOACs in Korean AF patients with LBW $(\leq 60 \mathrm{~kg})$ who were on oral anticoagulants ( $n=14,013$ with NOACs and $n=7,576$ with warfarin). ${ }^{3}$ NOACs were associated with lower risks of both stroke and major bleeding than warfarin in patients with $\mathrm{LBW}(\leq 60 \mathrm{~kg})$ and extreme $\mathrm{LBW}(<50 \mathrm{~kg})$.
Address for correspondence Eue-Keun Choi, MD, PhD, Department of Internal Medicine, Seoul National University Hospital, 101 Daehak-ro, Jongno-gu, Seoul 03080, Korea (e-mail: choiek17@snu.ac.kr).

Furthermore, on-label dosing of NOACs showed the largest risk reduction for the clinical outcomes compared with that of warfarin, whereas off-label overdosing showed similar outcomes as warfarin. Therefore, label adherence to NOACs, especially avoiding off-label overdosing, is important for AF patients with LBW. Another challenge in Asian patients with $\mathrm{AF}$ is that the safety zone of NOACs is narrower than that in non-Asians. ${ }^{4}$ In the Asian population, for example, the risks of ICH and major bleeding increased steeply as the concentration of edoxaban increased, whereas in non-Asians, the risk of ICH did not increase steeply. Considering the high prevalence of LBW and narrow safety zone of NOACs in Asian patients with $A F$, more evidence regarding the safety and optimal dosing of NOACs in AF patients with LBW is needed.

Patients with obesity are known to have better cardiovascular outcomes, a phenomenon known as the "obesity paradox." Similarly, NOAC trials have shown that obese patients with $\mathrm{AF}$ have lower risks of stroke and major bleeding. ${ }^{5}$ In line with previous studies, Boriani et al reported that a higher body mass index was associated with a lower risk of stroke/systemic embolic events (SEEs), whereas patients who are underweight $\left(<18.5 \mathrm{~kg} / \mathrm{m}^{2}\right)$ would partially be analyzed due to a limited number. ${ }^{6}$

In this issue of Thrombosis and Haemostasis, Boriani et al reported the efficacy and safety of edoxaban versus warfarin in AF patients with extreme body weights. ${ }^{7}$ They selected patients from the ENGAGE AF-TIMI 48 trial and categorized them into low, middle, and high body-weight groups as 5th percentile (LBW, $\leq 55 \mathrm{~kg}$ ), 45th to 55th percentile (MBW, $80-84 \mathrm{~kg}$ ), and 95th percentile (HBW, $\geq 120 \mathrm{~kg}$ ). Not surprisingly, the LBW group comprised frail individuals: they were older and more likely to be women, had higher prevalence of renal impairment and higher $\mathrm{CHADS}_{2}$ and HAS-BLED scores, and had a higher risk of falling than the MBW or HBW group. Furthermore, the LBW group had the lowest baseline received

September 2, 2020

accepted

September 2, 2020

published online

October 21, 2020 (c) 2020. Thieme. All rights reserved. Georg Thieme Verlag KG,

Rüdigerstraße 14,

70469 Stuttgart, Germany
DOI https://doi.org/ 10.1055/s-0040-1718413. ISSN 0340-6245. 
Table 1 Body weight of major pivotal clinical trials

\begin{tabular}{|c|c|c|c|c|}
\hline & $\begin{array}{l}\text { ROCKET-AF } \\
\text { (rivaroxaban) }\end{array}$ & $\begin{array}{l}\text { RE-LY } \\
\text { (dabigatran) }\end{array}$ & $\begin{array}{l}\text { ARISTOTLE } \\
\text { (apixaban) }\end{array}$ & $\begin{array}{l}\text { ENGAGE-AF } \\
\text { (edoxaban) }\end{array}$ \\
\hline \multicolumn{5}{|l|}{ Warfarin group } \\
\hline \multicolumn{5}{|l|}{$\begin{array}{l}\text { Mean or median } \\
\text { body weight }(\mathrm{kg})\end{array}$} \\
\hline Total & $81.6 \pm 18.9$ & $82.7 \pm 19.7$ & $82(70-95)$ & $N / A$ \\
\hline Asian/non-Asian & $\begin{array}{l}\text { Asian: } 66.4 \\
\text { Non-Asian: } 82.7\end{array}$ & $\begin{array}{l}\text { Asian: } 66.3 \pm 12.8^{\mathrm{a}} \\
\text { Non-Asian: } 82.7 \pm 19.2^{\mathrm{a}}\end{array}$ & $\begin{array}{l}\text { East-Asian: } 67 \text { (59-76) } \\
\text { Non-East Asian: } 84 \text { (72-97) }\end{array}$ & $\begin{array}{l}\text { Asian: } 66.4 \pm 13.1^{\mathrm{a}} \\
\text { Non-Asian: } 86.7 \pm 19.7^{\mathrm{a}}\end{array}$ \\
\hline $\begin{array}{l}\text { Proportion of } \\
\text { pts } \leq 60 \mathrm{~kg}\end{array}$ & $\mathrm{~N} / \mathrm{A}$ & $2 \%$ a,b & $12.3 \%^{\mathrm{a}}$ & $\begin{array}{l}\text { Total: } 10 \% \\
\text { Asian: } 33.6 \%^{\mathrm{a}} \\
\text { Non-Asian: } 6.2 \%^{\mathrm{a}}\end{array}$ \\
\hline \multicolumn{5}{|l|}{ NOAC group } \\
\hline \multicolumn{5}{|l|}{$\begin{array}{l}\text { Mean or median } \\
\text { body weight }(\mathrm{kg})\end{array}$} \\
\hline Total & $82.1 \pm 19.1$ & $\begin{array}{l}(150 \mathrm{mg}) 82.5 \pm 19.4 \\
(110 \mathrm{mg}) 82.9 \pm 19.9\end{array}$ & $80(70-96)$ & $\mathrm{N} / \mathrm{A}$ \\
\hline Asian/non-Asian & $\begin{array}{l}\text { Asian: } 67.3 \\
\text { Non-Asian: } 83.1\end{array}$ & $\begin{array}{l}\text { Asian: } 66.3 \pm 12.8^{\mathrm{a}} \\
\text { Non-Asian: } 82.7 \pm 19.2^{\mathrm{a}}\end{array}$ & $\begin{array}{l}\text { East-Asian: } 66 \text { (58-75) } \\
\text { Non-East Asian: } 84 \text { (72-97) }\end{array}$ & $\begin{array}{l}\text { Asian: } 66.4 \pm 13.1^{\mathrm{a}} \\
\text { Non-Asian: } 86.7 \pm 19.7^{\mathrm{a}}\end{array}$ \\
\hline $\begin{array}{l}\text { Proportion of } \\
\text { pts } \leq 60 \mathrm{~kg}\end{array}$ & $\mathrm{~N} / \mathrm{A}$ & $2 \%^{\mathrm{a}, \mathrm{b}}$ & $12.3 \%^{\mathrm{a}}$ & $\begin{array}{l}\text { HDER: } 9.7 \% \\
\text { LDER: } 9.9 \%\end{array}$ \\
\hline
\end{tabular}

Abbreviations: HDER, higher dose edoxaban regimen; LDER, lower dose edoxaban regimen; NOAC, nonvitamin K antagonist oral anticoagulant. Note: Values are mean \pm standard deviation, median (interquartile).

andicates the data in pooled total study population with warfarin and NOAC groups.

bLess than $50 \mathrm{~kg}$.

References: Wong KSL, Hu DY, Oomman A, et al. Rivaroxaban for stroke prevention in East Asian patients from the ROCKET AF trial. Stroke 2014;45 (6):1739-1747; Hori M, Connolly SJ, Zhu J, et al. Dabigatran versus warfarin: effects on ischemic and hemorrhagic strokes and bleeding in Asians and non-Asians with atrial fibrillation. Stroke 2013;44:1891-1896; Goto S, Zhu J, Liu L, et al. Efficacy and safety of apixaban compared with warfarin for stroke prevention in patients with atrial fibrillation from East Asia: a subanalysis of the Apixaban for Reduction in Stroke and Other Thromboembolic Events in Atrial Fibrillation (ARISTOTLE) Trial. Am Heart J 2014;168(3):303-309; Chao TF, Chen SA, Ruff CT, et al. Clinical outcomes, edoxaban concentration, and anti-factor Xa activity of Asian patients with atrial fibrillation compared with non-Asians in the ENGAGE AF-TIMI 48 trial. Eur Heart J 2019;40(19):1518-1527.

endogenous factor Xa activity, which indicated a higher bleeding risk.

The LBW group using warfarin showed the lowest time in therapeutic range, whereas the pharmacokinetic and pharmacodynamic profiles of edoxaban were consistent across the three different body-weight groups. The risks of stroke/SEE for higher dose edoxaban regimen (HDER) and lower dose edoxaban regimen (LDER) were similar to those of warfarin for each body-weight group. Both HDER and LDER significantly reduced major bleeding and nonmajor bleeding compared with warfarin, with greater reductions in the LBW and MBW groups.

In summary, Boriani et al show that edoxaban showed consistent benefit over warfarin in all the body-weight groups, especially a greater risk reduction in the LBW group. These results suggest reasonable explanations for the safety of edoxaban in patients with extreme body weights compared with that of warfarin, especially in LBW patients who are common in Asia.

However, some limitations need to be mentioned. First, the number of patients with pharmacokinetic/pharmacodynamic profiles in the edoxaban group was only 1,061-one-fourth of the study population. Second, it is unclear whether comorbidities among the three regimens (warfarin, HDER, and LDER) were equally distributed across the body-weight groups. Third, two-thirds of patients with LBW in this study also had renal impairment, so the results should be carefully interpreted to reflect not merely LBW patients, but frail patients with LBW and renal impairment. Lastly, the efficacy of stroke prevention of LDER in patients with LBW was not consistent with the main results of the ENGAGE AF-TIMI 48 trial. In the ENGAGE-AF trial, LDER was associated with a higher risk of ischemic stroke compared with warfarin; thus, this regimen was eventually not approved for stroke prevention in AF. In the present analysis, however, the performance of LDER in the LBW group was not associated with worse clinical outcomes compared with that of warfarin or HDER. Although the number of patients with LBW who were prescribed LDER and warfarin was insufficient to reach a strong conclusion, this could suggest the efficacy and safety of LDER in frail patients with LBW. Two-thirds of patients with LBW have renal impairment, which might increase their frailty. Recently, the ELDERCAREAF study reported that once-daily edoxaban $15 \mathrm{mg}$ showed risk reduction in stroke or systemic embolism without increasing the risk of major bleeding compared with placebo in very elderly Japanese patients with AF who are not eligible for standard oral anticoagulant therapy. ${ }^{8}$ This is in keeping with increasing data for the effectiveness and safety of NOACs in 
"real-world" elderly subjects. ${ }^{9}$ Where do we go from here? Stroke prevention in AF patients with extreme body weights is challenging, and the current study provides evidence of edoxaban efficacy in this special population, especially in individuals with LBW. Further studies would definitely be needed to provide evidence of NOACs for stroke prevention in frail patients with LBW.

Implications for body weight (and specifically, LBW) for AF component characterization have been recently described as the 4S-AF scheme (Stroke Risk; Symptoms; Severity of Burden; and Substrate $)^{10}$ and highlighted in the new 2020 European Guidelines: Merit Exploration. ${ }^{11}$ Risk factors and comorbidities (including body weight) are not static, and re-evaluation of changes over time is necessary. ${ }^{12,13}$ Differences between clinical trial and "real-world" settings are evident, and when used in everyday clinical practice, residual confounding from comorbidities may be evident. ${ }^{14}$ Challenges remain about optimizing adherence, drug persistence, and appropriateness of optimized prescribing. ${ }^{15,16}$

\section{Conflict of Interest}

S.-R.L.: none. E.-K.C.: research grant from Bayer, BMS/Pfizer, Biosense Webster, Chong Kun Dang, Daiichi-Sankyo, Samjin Pharm, Sanofi-Aventis, Seers Technology, and Skylabs.

\section{References}

1 Rocca B, Fox KAA, Ajjan RA, et al. Antithrombotic therapy and body mass: an expert position paper of the ESC Working Group on Thrombosis. Eur Heart J 2018;39(19):1672-1686

2 Wang KL, Lip GY, Lin SJ, Chiang CE. Non-vitamin K antagonist oral anticoagulants for stroke prevention in Asian patients with nonvalvular atrial fibrillation: meta-analysis. Stroke 2015;46(09): 2555-2561

3 Lee SR, Choi EK, Park CS, et al. Direct oral anticoagulants in patients with nonvalvular atrial fibrillation and low body weight. J Am Coll Cardiol 2019;73(08):919-931

4 Chao TF, Chen SA, Ruff CT, et al. Clinical outcomes, edoxaban concentration, and anti-factor Xa activity of Asian patients with atrial fibrillation compared with non-Asians in the ENGAGE AFTIMI 48 trial. Eur Heart J 2019;40(19):1518-1527

5 Proietti M, Guiducci E, Cheli P, Lip GY. Is there an obesity paradox for outcomes in atrial fibrillation? A systematic review and meta- analysis of non-vitamin $\mathrm{K}$ antagonist oral anticoagulant trials. Stroke 2017;48(04):857-866

6 Boriani G, Ruff CT, Kuder JF, et al. Relationship between body mass index and outcomes in patients with atrial fibrillation treated with edoxaban or warfarin in the ENGAGE AF-TIMI 48 trial. Eur Heart J 2019;40(19):1541-1550

7 Boriani G, Ruff CT, Kuder JF, et al. Edoxaban versus warfarin in patients with atrial fibrillation at the extremes of body weight: an analysis from the ENGAGE AF-TIMI 48 trial. Thromb Haemost 2020;121(02):140-149

8 Okumura K, Akao M, Yoshida T, et al; ELDERCARE-AF Committees and Investigators. Low-dose edoxaban in very elderly patients with atrial fibrillation. N Engl J Med 2020. Doi: 10.1056/NEJMoa2012883

9 Hohmann C, Hohnloser SH, Jacob J, Walker J, Baldus S, Pfister R. Non-vitamin $\mathrm{K}$ oral anticoagulants in comparison to phenprocoumon in geriatric and non-geriatric patients with non-valvular atrial fibrillation. Thromb Haemost 2019;119(06):971-980

10 Potpara TS, Lip GYH, Blomstrom-Lundqvist C, et al. The 4S-AF scheme (stroke risk; symptoms; severity of burden; substrate): a novel approach to in-depth characterization (rather than classification) of atrial fibrillation. Thromb Haemost 2020 (e-pub ahead of print) . Doi: 10.1055/s-0040-1716408

11 Hindricks G, Potpara T, Dagres N, et al; ESC Scientific Document Group. 2020 ESC guidelines for the diagnosis and management of atrial fibrillation developed in collaboration with the European Association of Cardio-Thoracic Surgery (EACTS). Eur Heart J 2020. Doi: 10.1093/eurheartj/ehaa612

12 Chao TF, Liao JN, Tuan TC, et al. Incident co-morbidities in patients with atrial fibrillation initially with a CHA2DS2-VASc score of 0 (males) or 1 (females): implications for reassessment of stroke risk in initially 'low-risk' patients. Thromb Haemost 2019;119 (07):1162-1170

13 Chao TF, Lip GYH, Lin YJ, et al. Incident risk factors and major bleeding in patients with atrial fibrillation treated with oral anticoagulants: a comparison of baseline, follow-up and delta HAS-BLED scores with an approach focused on modifiable bleeding risk factors. Thromb Haemost 2018;118(04):768-777

14 de Vries TAC, Hirsh J, Xu K, et al. Apixaban for stroke prevention in atrial fibrillation: why are event rates higher in clinical practice than in randomized trials?-a systematic review Thromb Haemost 2020;120(09):1323-1329

15 Pritchett RV, Bem D, Turner GM, et al. Improving the prescription of oral anticoagulants in atrial fibrillation: a systematic review. Thromb Haemost 2019;119(02):294-307

16 Hylek EM. Treatment persistence in atrial fibrillation: the next major hurdle. Thromb Haemost 2018;118(12):2018-2019 